\title{
Infames e penetras no universo da leitura: princípios da arqueologia foucaultiana em uma análise de discursos sobre essa prática
}

\author{
Infamous and intruders in the universe of reading: an analysis of discourses on this \\ practice according to the principles of Foucault's archeology
}

Luzmara CURCINO

Universidade Federal de São Carlos (UFSCar)

http://orcid.org/0000-0003-3555-1446

\begin{abstract}
RESUMO: Neste artigo, à luz de princípios e conceitos de "A Arqueologia do Saber", e de outras obras de Michel Foucault, empreendo uma análise de discursos sobre a leitura a partir de notícias que emergem com relativa frequência com histórias de pessoas que viviam na miséria e que graças à leitura melhoraram de vida. Nessas notícias são atualizados discursos consensuais sobre essa prática e representações idealizadas do que é ser leitor. Na enunciação do prodígio dessas vidas "ínfimas" e desses sujeitos "infames" se explora, em tom de espetáculo tão ao gosto da mídia nacional, uma série de estereótipos na caracterização desses "penetras" da cultura letrada, apresentados como empreendedores de si mesmos. Nessas notas, a leitura é evocada como álibi para justificar vergonhosas desigualdades socioculturais e naturalizar certas formas de exercício do poder, e não como uma prática em seu potencial efetivamente emancipatório.
\end{abstract}

PALAVRAS-CHAVE: Discursos sobre a leitura. Mídia. Sujeitos infames. Meritocracia. A Arqueologia do Saber.

ABSTRACT: Based on principles and concepts from "The Archeology of Knowledge", and other works by Michel Foucault, in this article, I analyze discourses about reading inscribed in news published in the Brazilian media with stories of people who lived in poverty and, through the reading, have improved their lives, especially from an economic point of view. In this news, we are faced with hegemonic discourses about reading and with idealized representations of what it means to be a reader. In the enunciation of the prodigy of these "tiny" lives and of these "infamous" persons, a series of stereotypes is explored in the characterization of these "intruders" of high culture, presented as entrepreneurs of themselves, in a tone of spectacle so in tune with the national media. In these notes, reading is evoked as an alibi to justify shameful socio-cultural inequalities and naturalize certain forms of exercising power, and not as a practice in your effectively emancipatory potential.

KEYWORDS: Discourses about reading. Media. Infamous persons. Meritocracy. The Archaeology of Knowledge.

\section{Introdução}

“A Arqueologia do Saber" é uma dessas obras fundamentais às quais em geral se volta constantemente e com as quais se tem a impressão de haver sempre o que aprender. Essas características são em geral lembradas como próprias dos clássicos. $\mathrm{O}$ que se aprende com esse tipo de "obra" pode ser incorporado de tal modo que se passa a ler e a ver "as palavras e as coisas" segundo uma "ordem discursiva" que a condição de 
clássico institui. Tornando-se um clássico, uma obra então estabelece todo um "campo enunciativo", um horizonte de discursividades quanto ao que dizer dela, a partir dela e à sua maneira e em seu estilo. Elas também passam a figurar entre as obras incontornáveis de um campo de estudos, e por isso nos são apresentadas, recomendadas e lidas no âmbito de instituições ${ }^{1}$, e sob seus auspícios, de modo quase sempre ritualizado e reverente. São, portanto, obras a que se é apresentado, às quais se lê e cujos enunciados se incorpora. Sua incorporação se indicia não apenas no que se diz consoante àquilo que nelas foi dito, com base nelas e a partir delas. Sua incorporação também pode ser observada na apropriação de seu modo de estetizar o dito, na mimetização de sua maneira de dizer.

Essa incorporação das obras pode atingir níveis segundo os quais aqueles que delas se apropriam podem acreditar dizer coisas originais, de forma original, esquecendo os detalhes da dívida com esses clássicos, dívida que se traduz em uma repetição do que ali se disse, repetição-dívida, de uma dívida nem sempre é assumida ou lembrada, ou então de um dívida que se reconhece, e que se reconhece por vezes em excesso, na sua repetição infinda. Grandes obras impõem essas intensidades em suas recepções. Não se pode ser indiferente a elas e ao impacto que produzem. Trata-se de um funcionamento próprio da leitura de certas obras, dessas obras que mobilizam nossos afetos, que nos incitam a uma apropriação intensa, traduzida seja na dívida reconhecida, pela citação incessante do que ali se disse, seja na dívida que se esquece ou que se silencia, ecoada na reprodução sem créditos do que nela foi dito, assim como na imitação de seu estilo de dizer.

"A Arqueologia do Saber" ocupa, sem dúvida alguma, um lugar de honra no panteão dessas obras a que chamamos de clássicas. Há muitos devedores gratos, reconhecidos, como há também os esquecidos, distraídos, que ainda assim, nessa sua recitação clandestina, a homenageiam. Como leitores da "Arqueologia", podemos nos encontrar em ambas as categorias. Que seja!

E esse é, sem dúvida, um dos tantos aprendizados que nos lega a abordagem discursiva assumida pelo filósofo Michel Foucault em sua "Arqueologia”, dedicada a apresentar, em seus vários e complexos aspectos, o funcionamento próprio dos

\footnotetext{
${ }^{1}$ Devo meu encontro com essa obra e autor às aulas ministradas pela Professora Maria do Rosário Gregolin na UNESP-Araraquara, à leitura de suas publicações - entre outras, a de seu livro "Foucault e Pêcheux na análise do discurso - diálogos e duelos" (2004) - e aos encontros por ela coordenados do GEADA - Grupo de Estudos de Análise do Discurso de Araraquara, de cuja história tenho o orgulho de fazer parte <http://geadaararaquara.blogspot.com/p/sobre-o-geada.html $>$.
} 
discursos, dos discursos que são, em si mesmos, práticas, e como tal, que respondem a regras. Ser exposto a essas injunções da recepção de um clássico e ao funcionamento dos discursos não significa se livrar dos riscos dessas formas de sua apropriação: o de esquecer ou o de silenciar a dívida, ou o de lembrar demasiadamente, e de se proteger a tal ponto na segurança de sua referência de modo a se perder nessa dívida, e não se arriscar para além dos limites da obra. Ainda assim, mesmo correndo esses riscos, vale a pena a leitura, os retornos, os usos que lembram e os usos que esquecem do que se encontra enunciado nessa obra e em outras desse mesmo autor.

A "Arqueologia", sua leitura, os modos como nela nos apoiamos e como a ela nos referimos são um belo exemplo da vultosa reflexão que Michel Foucault nos legou há cinco décadas, e que nos apresenta sobre a produção e institucionalização dos discursos, sobre seu funcionamento, que tanto fornece o que dizer, na mesma medida em que regula esse dizer, garantindo a esse dizer suas condições de enunciabilidade e de recepção. Essa oferta e regulação do dizer implicam procedimentos de seleção do que é dizível, como também limites quanto aos modos de atualizar esse dizível. Esses limites definem quem pode dizer, de que posições-sujeito, em nome de que instituições, segundo quais ritos e conforme quais circunstâncias. Pode-se ignorar esses limites, mas esses limites não ignoram nosso dizer. Se não considerados ou se não conhecidos, correse o risco de não se fazer ouvir, crer ou compreender, corre-se o risco de se encontrar fora do dizer institucionalmente e consensualmente estabelecido como verdadeiro, para um dado tempo e lugar.

Michel Foucault se esmera em detalhar em sua "Arqueologia" esse modo complexo de funcionamento dos discursos que regem nossas práticas, crenças, valores, que estabelece a permanência ou a mudança dessas práticas, crenças, valores, portanto, dos sujeitos, sob o pedágio da história. Ao dedicar-se à descrição dessas regras do funcionamento dos discursos, de sua ação sobre todo e qualquer dizer, de todo e qualquer sujeito, de seu impacto sobre práticas, crenças, valores, enfim, sobre quem somos, o filósofo não buscou formular prescrições, como às vezes erradamente se lê. Ele não desempenhou o papel de um prescritivista, mas sim o de um exímio “diagnosticador do presente", o de um sagaz observador de "quem nós somos", a partir da descrição dos dispositivos de diferentes ordens responsáveis por termos nos tornado quem somos, como sociedade e como sujeitos, e isso a partir de sua rigorosa e generosa análise dos discursos. 
Tendo no horizonte os desafios e riscos na apropriação das obras, a consciência de que ter consciência dos riscos não nos livra de a eles nos expor, neste artigo, à luz de princípios e conceitos da "Arqueologia" foucaultiana, mas também recorrendo à leitura de outras obras desse autor, empreendo uma análise, breve e pontual, de certos discursos sobre a leitura que circulam entre nós, a nosso respeito e em nossa sociedade, discursos estes de diferentes durações que são convocados em circunstâncias muito diversas e que são atualizados sob formas muito específicas de enunciação e por distintos sujeitos, em nome e a partir de diferentes instituições e para finalidades nem sempre adequadas que, por sua desvirtuação, exigem de nós um posicionamento ético e firme.

Diante da variedade de fontes, a partir das quais são atualizados discursos sobre a leitura hoje em dia $^{2}$, busco neste artigo me ater à depreensão de representações da leitura e de nós como leitores a partir da análise de alguns textos bastante peculiares, a saber, notícias que são produzidas e que circulam com relativa frequência em jornais e revistas brasileiros sobre pessoas em situação de extrema vulnerabilidade e marginalidade social, tais como catadores de lixo e moradores em situação de rua, cuja excepcionalidade que as tornam 'noticiáveis' é exatamente terem sido flagradas com livros, e tendo se tornado leitores puderam mudar radicalmente seu destino social ${ }^{3}$. Nessas notícias nos deparamos com discursos hegemônicos sobre a leitura, com representações idealizadas do que é ser leitor ${ }^{4}$.

$\mathrm{Na}$ análise, discorro sobre o caráter enviesado da alusão a esses discursos e representações, que são mobilizados para fomentar nossa cegueira social, para desviar nosso olhar das razões político-ideológicas da extrema desigualdade socioeconômica com a qual convivemos, ou melhor, para justificar essa desigualdade. É, portanto, não sem uma grande dose de cinismo, que em vários desses textos a leitura é usada como mote para se difundir a ideologia da meritocracia e com ela naturalizar hierarquias entre os sujeitos, outorgando certas formas de exercer poder a uns poucos na mesma medida em que se destitui esse poder da maioria.

Constato, nessa análise, o caráter episódico, espetacular, superficial, efêmero, estereotipado e inócuo dessas notícias acerca desses sujeitos, que na maior parte do

\footnotetext{
${ }^{2}$ Este trabalho resulta das pesquisas que realizamos junto ao LIRE - Laboratório de Estudos da Leitura na UFSCar, dedicadas à análise de discursos sobre a leitura a partir de diferentes fontes e meios. Cf. cadastro do grupo no Diretório Nacional dos Grupos de Pesquisa do CNPq: http://dgp.cnpq.br/dgp/espelhogrupo/43446.

${ }^{3}$ Cf. também a esse respeito, Curcino (2020), artigo em que apresento análise de um conjunto semelhante de dados, comparando diferentes textos cujo mote da leitura se presta a esse mesmo objetivo.

${ }^{4}$ Cf. Britto \& Barzotto (1998); Abreu (2001); Bayard (2007); e Curcino \& Varella (2014).
} 
tempo de suas vidas são invisíveis socialmente, dessa invisibilidade ligada à sua origem de classe, dessa invisibilidade responsável sobremaneira pela indiferença de nossa sociedade e pela inércia política frente a suas condições miseráveis e indignas de vida. Assim, apoiando-me em princípios e conceitos de "A Arqueologia do Saber", bem como em outras obras do filósofo, busco aqui depreender seja a reiteração seja a subversão de certos discursos sobre a leitura, analisando-os em sua "regularidades discursivas", na relação dos enunciados presentes nessas notícias sobre esses leitores improváveis com aqueles do "arquivo" de enunciados que já foram efetivamente produzidos sobre a leitura, em sua duração histórica, em seu valor de verdade, em seu poder objetivamente e subjetivante dos sujeitos como leitores e de suas práticas de leitura.

\section{1. "A Arqueologia do Saber": uma teoria da formação dos discursos}

Michel Foucault, em “A Arqueologia do Saber”, questiona uma série de certezas (acolhedoras e confortáveis) com as quais estamos bastante familiarizados. Entre essas certezas sobre as quais ele se interroga e nos interroga, ele nos convida a questionar certas unidades (naturalizadas, espontâneas, homogêneas) como a do 'livro', da 'obra' e do 'autor'. Essas são "unidades" cruciais no campo de que ele se ocupou na "Arqueologia": aquele da história da formação de certos saberes. Elas são cruciais na medida em que são os vetores comuns das ideias que podem vir a se constituir como ciência, ou seja, são cruciais na medida em que fazem parte das condições que determinam o processo de institucionalização do que é enunciado, em um dado tempo e lugar e sobre um dado tema, sob o signo de um saber e de uma ciência que virá a ser.

Essas unidades também são fundamentais para a compreensão do tipo de prática a que tenho me dedicado em minhas pesquisas: a leitura. Tanto a 'leitura', tal como ela

é discursivizada, quanto a figura do 'leitor', segundo representações idealizadas e compartilhadas socialmente, compõem o rol dessas unidades que provém de “continuidades irrefletidas", para empregar a expressão usada por Foucault (2000, p. 28 29). A 'leitura' e o 'leitor', assim como o 'livro', a 'obra' e o 'autor, são em geral concebidos como signos cujo significado se nos apresenta de maneira imediata, completa, simples e muito familiar, ou seja, evidente. Sem história e sem arestas, elas se nos apresentam como um tranquilo "é assim porque sempre foi assim". No entanto, tal como observa o filósofo, particularmente sobre o 'livro': 
Por mais que o livro se apresente como um objeto que se tem na mão; por mais que ele se reduza ao pequeno paralelepípedo que o encerra, sua unidade é variável e relativa. Assim que a questionamos, ela perde sua evidência; não se indica a si mesma, só se constrói a partir de um campo complexo de discursos. (FOUCAULT, 2000, p. 26)

Reconhecer e contornar a "evidência" resultante dessas continuidades, da existência dessas unidades, é o grande desafio para a análise do discurso a que nos propõe o filósofo: o de "acolher cada momento do discurso em sua irrupção de acontecimento" (FOUCAULT, 2000, p. 28), na atualidade de sua emergência, e na dispersão temporal de que deriva. Ele nos convida, assim, a tratar o discurso na peculiaridade de sua emergência e a "mostrar [que essas continuidades e as unidades que lhe equivalem] são sempre o efeito de uma construção [discursiva] cujas regras devem ser conhecidas" (FOUCAULT, 2000, p. 29). Com isso, ele não propõe simplesmente que abandonemos essas continuidades e unidades. Diferentemente disso, ele afirma que nosso objetivo deve ser o de

arrancá-las de sua quase-evidência, de liberar os problemas que colocam; [...] Trata-se de reconhecer que elas talvez não sejam, afinal de contas, o que se acreditava que fossem à primeira vista. Enfim, que exigem uma teoria; e que essa teoria não pode ser elaborada sem que apareça [em sua dispersão que lhe é própria] o campo dos fatos do discurso a partir do qual [essas continuidades e unidades] são construídas (FOUCAULT, 2000, p.29).

É precisamente essa “teoria" que Michel Foucault vai nos apresentar em seus contornos, sempre suscetíveis de alargamentos em função de nossos objetos e de nossas perguntas. Para ele, primeiramente, é preciso suspeitar das continuidades/unidades que nos chegam assim naturalizadas; em seguida, é preciso partir dos enunciados efetivamente produzidos; para enfim, considerar esses enunciados em sua dispersão de "acontecimentos discursivos" e na sua emergência específica, efetiva, cuja descrição deve ser guiada sempre pelo questionamento: "como apareceu um determinado enunciado, e nenhum outro em seu lugar?" (FOUCAULT, 2000, p. 31).

[é preciso] compreender o enunciado na estreiteza e singularidade de sua situação; de determinar as condições de sua existência, de fixar seus limites da forma mais justa, de estabelecer suas correlações com os outros enunciados a que pode estar ligado, de mostrar que outras formas de enunciação ele exclui (FOUCAULT, 2000, p. 31).

Em relação aos discursos sobre a leitura, a depreensão de seus "objetos", "tipos de enunciação", "conceitos" e "escolhas temáticas", pode se dar a partir de diferentes fontes. Ao se falar da leitura, há certos objetos de discurso mais regulares: há o que se diz sobre ela, sob a forma de recomendações tanto aquelas que prescrevem que se deve 
ser leitor, quanto aquelas relativas ao que ler e ao modo como se deve ler; há ainda dizeres sob a forma de asserções de que se deve ler sempre; de que se deve ler prioritariamente livros; de que se deve ler por prazer; de que se deve ler de um jeito e não de outro, de acordo com rituais e procedimentos diferentes adotados por comunidades leitoras distintas, em conformidade com campos variados, no interior dos quais se é exposto a regras de legitimação também variadas quanto ao modo como valoram certos gêneros, temas, estilos, objetos culturais, na mesma medida em que menosprezam outros, tidos por seus avessos ou em escalas decrescentes de valor.

Aprendemos com a "Arqueologia", quando analisamos o que se enuncia sobre uma prática como a leitura, no caso de nossa análise, que o dizer a esse respeito e as práticas que a ele se relacionam constituem-se conforme uma "ordem discursiva", segundo a qual não se fala de qualquer coisa quando se fala da leitura, nem de qualquer modo, nem em qualquer circunstância, nem com qualquer sujeito. Também não é qualquer sujeito que está autorizado a enunciar com propriedade sobre a leitura, nem que se sente no direito para tal, e que mesmo se pronunciando a respeito, e segundo as formas estabilizadas e autorizadas de enunciar, pode ainda assim não ser reconhecido como sujeito legítimo para isso, a ponto de seu dizer ser ignorado, menosprezado ou ridicularizado ${ }^{5}$.

Assim, a "ordem do discurso" atua sobre o que se diz sobre a leitura, de modo a fazer a triagem e a institucionalização de formas consagradas e/ou prototípicas de se referir a essa prática, assim como de formas condenáveis que comporiam o não-dizível a seu respeito; essa "ordem" também determina as circunstâncias, os sujeitos e os contextos que nos interpelam a falar dessa prática, assim como ela estipula as interdições que nos lembram os protocolos a seguir quando nos colocamos a falar dela, guiados pelas representações que compartilhamos acerca do que não se deve/nem se pode falar a esse respeito, sob o risco de ter seu dizer desqualificado e de ser desqualificado em função do seu dizer.

Em toda e qualquer sociedade, os discursos, enfim, os enunciados sobre a leitura não são um dizer à parte, autônomos em relação a outros. Suas margens, tal como afirma o filósofo sobre todo e qualquer enunciado e discurso, "são povoadas de outros enunciados" e de outros discursos (FOUCAULT, 2000, p. 112), provenientes de outros

\footnotetext{
${ }^{5}$ A esse respeito, ver a análise em Curcino (2018) sobre as formas de depreciação que em geral acompanham, por contraste com ex-presidente Fernando Henrique Cardoso, a representação do presidente Luís Inácio Lula da Silva, na mídia, como leitor, embasada em discursos sobre a leitura que circulam de maneira legitimada entre nós.
} 
campos enunciativos, campos que fornecem os "temas correlacionáveis" ao que se diz sobre essa prática, e que delineiam o lugar e o status que esse dizer pode ocupar.

Os discursos sobre a leitura cotejam assim outros discursos que: i) justificam hierarquias socioculturais entre os sujeitos, há muito naturalizadas e segundo representações coletivas generalizantes (o brasileiro não lê; o jovem de hoje em dia não lê; o pobre é pobre porque não lê); ii) reproduzem a lógica meritocrática (ser leitor é uma questão de interesse individual: lê quem quer, quem se esforça, quem é dedicado, quem "corre atrás"); iii) difundem a teoria do dom, do gosto individual (alguns têm dom para a leitura; alguns nasceram pra isso; alguns gostam de ler e têm bom gosto, outros não); iv) atribuem as culpas a agentes diversos, sem problematizar as condições sociais, materiais, essenciais sem as quais dificilmente podemos nos tornar leitores (os pais não leem; os professores não leem; os alunos não leem.); v) ancoram-se em vulgatas de teorias da interpretação (a leitura é singular e cada um tem sua leitura, o que leva a um relativismo cômodo e acomodante, que afeta o modo como ensinamos essa prática e nos relacionamos com ela); vi) são, por fim, difundidos em abordagens de ensino adotados pela instituição escolar que recebe e replica esses discursos sobre a leitura que circularão amplamente em nossa sociedade (a leitura deve priorizar os cânones/ a leitura deve contemplar o que os jovens gostam; deve-se ler todos e quaisquer gêneros em especial aqueles que os jovens têm familiaridade etc.).

Esses são discursos evocados quando se fala da leitura, porque fornecem evidências explicativas, algumas providas de outros campos de emergência (o discurso da meritocracia e do dom, por exemplo, ou a vulgata de alguns discursos científicos). Esses discursos ancoram o dizível sobre a leitura numa lógica já conhecida, construída para circular como consenso, por isso de mais fácil adesão e reprodução.

\section{Da infâmia à primeira página:}

Há vidas e sujeitos que são lembrados somente e a partir de seu "encontro com o poder". É com base nessa constatação que Michel Foucault publica “A vida dos homens infames" (2003a). Inspirada nessas suas reflexões, o encontro entre sujeitos e o poder de que trato neste artigo se dá entre as instituições que nos fornecem diariamente o que saber do mundo e dos sujeitos. De um lado, encontram-se instituições com poder de atuar como extensões e amplificações do olhar e da escuta coletiva, dispositivos de fazer 
ver, de fazer ouvir e de fazer crer $^{6}$; de outro, sujeitos que valem aquilo que em uma sociedade capitalista e hierarquizada como a nossa define de antemão como digno de valor. Alguns destes sujeitos se encontram desde sempre à margem. São peças que não se encaixam no quebra-cabeças dos modos de ser e estar normalizados. São aqueles de que preferimos ignorar a sua existência, no conforto de nossa pretensa, e muitas vezes ostentada, adequação.

De sua existência perturbadora somos lembrados quando se comportam em dissonância com o que imaginamos dever ser o seu destino, sua rotina, suas vidas. É esse estranhamento - misto de espanto e surpresa - que atrai nossa atenção. A razão desse nosso estranhamento é a de saber que certos sujeitos leem, quando o estereótipo a seu respeito se sustenta em ideia contrária. E é justamente por terem sido flagrados lendo ou na companhia de livros, que a eles são dedicadas algumas linhas e que a sua existência ignorável se torna digna de algumas notas. O caráter inusitado e improvável de sua existência como leitores é motivo suficiente para que sua infâmia plena seja suspensa temporariamente, e com isso gozem de algumas linhas de notoriedade nas páginas e telas de jornais, revistas, programas televisivos, postagens em portais ou comentários em redes sociais. A mídia assume seu lugar de honra nesse dispositivo contemporâneo de fazer ver e crer, mesmo aquilo que não é ou não está, e de tornar invisível e inverdade aquilo que, no entanto, seria e estaria.

Essas vidas a que me refiro são aquelas ignoradas, porque miseráveis e marginalizadas, que se tornam notícia simplesmente porque foram vistas com livros, porque guardam esses livros, os leem, e algumas delas eventualmente puderam driblar o determinismo de sua condição em função desse contato. Essas vidas têm histórias muito parecidas, e o pouco que se explora e que se ostenta de suas narrativas, na mídia, espanta, comove e ao mesmo tempo doutrina.

São catadores de lixo e/ou moradores em situação de rua que se tornam notícia porque em sua miséria total entesouraram o livro, esse objeto que se tornou lixo e que é alçado, nessas notícias, a um fetiche decisivo nessas vidas. A presença desse objeto nos

\footnotetext{
${ }^{6}$ Segundo Curcino \& Piovezani (2014, p. 35), o "dispositivo" para o filósofo Michel Foucault "equivale a um conjunto de formas históricas de agenciamento e de coerção do saber e do poder que atuam em um dado tempo e espaço e que se materializam de formas diversas". Como tal, ele agencia "um certo número de enunciados, de discursos e, consequentemente, de todas as formas de representações que podem formá-los e deles provirem/derivarem" (FOUCAULT, 2003b, p. 14), materializado e depreensível sob a forma "de instituições e de leis, de coisas e de ideias, de atos e de práticas, de palavras e de textos, de ditos e de não ditos" (COURTINE, 2011, p. 25).
} 
espaços insalubres e precários onde vivem esses sujeitos frustra toda e qualquer estatística, expectativa ou 'normalidade'. Ela é quase da ordem do nonsense.

Em geral, o que se diz e o que se fica sabendo desses sujeitos e de suas histórias não têm tanto relevo, não ocupa as principais páginas ou espaços da mídia tradicional, nem conta com grandes artifícios em sua elaboração. Apesar disso, textos com esse mesmo tema emergem com relativa regularidade. $\mathrm{O}$ que neles acende nossa curiosidade e rapta nossa atenção é esse encontro entre gente destinada a não ler e esse objeto ainda hoje rarefeito e sacralizado, e essa prática para os que, entre nós, têm tempo e meios.

Meu interesse por estes textos da mídia, que tiram provisoriamente do anonimato esses sobreviventes do lixo e da miséria em função do caráter surpreendente de seu interesse por livros e pela leitura, é o mesmo que tem orientado minhas pesquisas e aquelas que oriento acerca dos discursos sobre a leitura e de seu funcionamento em nossa sociedade. É porque nesses textos, que parecem priorizar esses eventos singulares, essas vidas em geral esquecidas, encontra-se antes a retomada de consensos, não apenas relativos aos discursos de viés cultural sobre a leitura, mas também, e talvez principalmente, aqueles responsáveis pelas divisões sociais dos sujeitos em nossa sociedade, aqueles que fornecem as explicações e justificativas para que essas divisões sejam tais como são e nossa relação com elas seja com isso naturalizada. Esses discursos sobre a leitura não são, portanto, em nada inócuos.

Por mais que o discurso seja aparentemente bem pouca coisa, as interdições que o atingem revelam logo, rapidamente, sua ligação com o desejo e com o poder. [...] o discurso não é simplesmente aquilo que traduz as lutas ou os sistemas de dominação, mas aquilo pelo que se luta, o poder do qual queremos nos apoderar. (FOUCAULT, 1996, p. 8 e 9)

\section{Livros, lixo e redenção}

Com uma simples busca na internet, nos deparamos com uma série de textos que têm em comum abordarem como tema as narrativas de vida desses leitores improváveis, desses penetras da cultura letrada ${ }^{7}$. Cada um desses textos testemunha esse encontro entre as instituições que constituem o dispositivo de fazer ver e de tornar invisível, na atualidade, e essas vidas até então ignoradas, e cuja única razão para que fossem eleitas

\footnotetext{
${ }^{7}$ Poderíamos nomeá-los, nos termos de Jean Hébrard (2005), em seus estudos sobre autodidatas do século XVIII, como "novos leitores", aqueles que de início foram alijados, em função de suas origens sociais, do acesso a uma formação adequada, institucional, regular e precoce da prática de leitura, mas que mesmo assim entraram, ainda que "por arrombamento", nos termos de Hébrard, nesse universo letrado, cujo modo de apropriação, embora busque mimetizar aquele próprio dos sujeitos que, desde o berço, tiveram o direito de aceder a esse universo, deles em geral se diferencia, marcados pela singularidade de suas existências.
} 
entre tantas outras - para serem mostradas, para se tornarem notícia, para transmitirem uma mensagem com vistas à ratificação das formas legitimadas de comportamento social - liga-se a seu contato com livros e a suas experiências com a leitura.

São textos de jornais ou revistas, publicados em seus sites oficiais e replicados virtualmente em portais de notícia e em redes sociais diversas. São textos cujo mote principal é tratar: 1) de livros encontrados no lixo e dos sujeitos que os encontraram e que salvaram esse objeto de seu destino trágico; ou 2) dos sujeitos que vivendo do lixo se encontraram com livros, e tendo se encontrado com esse objeto puderam contrariar o seu destino trágico.

No caso dos primeiros, as narrativas destacam esse gesto nobre desses sujeitos que, mesmo na miséria material e cultural que lhes foi legada, mesmo não sendo leitores, mas reconhecendo o valor e o destino trágico desse objeto raro, desse luxo tão infrequente em suas vidas, de alguns livros jogados no lixo, os resgatam, os leem, quando sabem ler e quando podem fazê-lo, ou simplesmente os guardam, como tesouro, como reserva de dignidade, como fetiche com poder de produzir certa distinção entre esses sujeitos e os demais de seu meio. A mera salvaguarda desse objeto sacralizado lhes garante alguma honra ou autoridade.

No caso dos segundos, as narrativas destacam o poder emancipatório dos livros e da leitura, seu poder salvacionista ${ }^{8}$, por isso são representados como fonte de esperança de sucesso, como meio potente de formação e como elemento decisivo na mudança das condições de vida. A sorte do encontro, em geral tardio, errático e fortuito com os livros e a leitura, é, neste caso, descrita como um ponto de inflexão em suas histórias de vida, e, por isso, essas narrativas assumem um tom solene, adotam as metáforas conhecidas e os adjetivos consensuais fornecidos pelos discursos legitimados sobre a cultura letrada e seu objetivo-fetiche, o livro.

O enunciador midiático, nesses dois tipos de narrativa sugere ou simplesmente outorga à voz daqueles de que fala esses discursos consensuais sobre a leitura. São discursos cujo poder reside em sua plena naturalização, obviedade, transparência e valor de verdade, tamanha sua repetição e institucionalização.

Essas vidas ignoráveis, invisíveis, de repente interessam. E aquilo que faz com que sejam vistas e faladas (ainda que superficial e brevemente, para depois voltarem

\footnotetext{
${ }^{8}$ Sobre esse caráter salvacionista da leitura, e outros poderes que lhe são atribuídos de modo muitas vezes ingênuo e em consonância com discursos que enfatizam, de maneira elitista e miserabilista, esse papel da leitura, cf. Britto (2016).
} 
para seu esquecimento) é exatamente a estranheza, a surpresa de seu contato com o livro, da presença do livro e da leitura entre aqueles de que não se espera isso. Elas também interessam, e talvez principalmente por isso, porque fornecem exemplos condizentes com ideias, posicionamentos e valores dominantes aos quais aderem, visam e propagam as instituições que tornaram visíveis essas vidas até então desconhecidas, silenciadas e à margem.

Em alguns desses textos se alude a projetos sociais de promoção da leitura desenvolvidos junto a comunidades de catadores de lixo ou moradores de rua, de modo a constituir bibliotecas com esses livros encontrados no lixo e com aqueles doados/descartados com vistas a formar leitores junto a essas comunidades. Outros textos relatam as iniciativas individuais de sujeitos que tendo encontrado livros no lixo constituíram bibliotecas de uso pessoal ou coletivo e se tornam exemplos de vida e agentes comunitários. Alguns desses textos focalizam histórias de vida de alguns indivíduos que, mesmo vivendo na rua e/ou tendo de sobreviver com recursos obtidos no lixo, encontraram-se ao acaso com livros no lixo, ou tiveram acesso, também por acaso, a um livro específico, e puderam, em função desse contato inaugural e auspicioso, se tornar leitores, e uma vez leitores se emanciparem podendo assim abandonar sua vida precária, e até gozarem de uma relativa e breve notoriedade nesses textos da mídia.

Vou me deter na análise de um exemplo deste último conjunto, de modo a depreender o que é enunciado sobre esse sujeito por essas instituições responsáveis pelo dizer e pelo mostrar públicos, e quais discursos sobre a leitura, assim como quais discursos adjacentes, que ali se expressam, são retomados, reforçados, atualizados, ao se falar desses sujeitos e dessa prática. Vou buscar olhar mais de perto como esses seus cinco minutos de fama e visibilidade lhes foi concedido em função de um dia ter cruzado com o livro e com a leitura.

\section{De catador de lixo a médico}

Trata-se de uma história de vida cuja narrativa encontrou ampla repercussão, inclusive na mídia televisiva, diante do que se considera ser uma conquista improvável: a de um pobre, que viveu de catar lixo, cursar medicina e de se tornar médico no Brasil. Foram várias as matérias a seu respeito. Os títulos enfatizam o papel da leitura em sua conquista: "Com livros achados no lixo, morador do DF aprende a ler e se torna 
médico"; "Pegava livros no lixo, ex-catador de Brasília conta como virou médico"10; Menino pobre descobre vocação nos livros que catava no lixo e vira médico" ${ }^{11}$; "Inspirado nos livros do lixo, ex-catador virou médico"12.

No corpo desses textos, essa ênfase se mantém:

(1) Órfão de pai aos 2 anos e tendo a mãe alcoólatra e um dos sete irmãos traficante, o médico de Brasília Cícero Pereira Batista, de 33 anos, conseguiu vencer as adversidades estudando a partir de livros que retirava do lixo. [...] Junto com as sobras de alimentos descartados no lixo, Batista recolhia todos os livros que encontrava e vinis de Beethoven e Bach, atualmente suas inspirações. [...] "Amo Bach e Mozart. Junto com os livros, eles me salvaram. Eles falavam mais alto que a fome e me transportavam para outros mundos." [...] "Fui juntando as sílabas e compreendendo as sentenças e palavras. Quando entrei na escola para fazer o primário, já sabia ler, escrever e fazer as operações fundamentais". 13

(2) Quando tinha 5 anos, o menino pegava o que podia ser útil no lixo. Inclusive livros, apesar de não saber ler. Com o tempo, conta o ex-catador, eles foram servindo de inspiração. Ficava mais feliz quando encontrava títulos de biologia, ciências. Certa vez encontrou alguns volumes da Enciclopédia Barsa e "descobriu Pedro Álvares Cabral, a literatura, a geografia". ${ }^{14}$

As narrativas nestes textos são praticamente idênticas a tantas outras histórias que viraram notícia e que uma simples procura na internet testemunha a proficuidade desse 'mote' para matérias jornalísticas: alguém de origem humilde, submetido a uma condição de vida miserável e precária, cuja família é obrigada a buscar seu sustento em trabalhos informais e insalubres, em geral, como catadores e recicladores de lixo, e que, graças ao contato com livros descartados e encontrados no próprio lixo, puderam assim driblar seu destino.

\footnotetext{
9 "Com livros achados no lixo, morador do DF aprende a ler e se torna médico", escrito por Raquel Morais, G1 - Distrito Federal, publicado em 04/09/2014. Disponível em: <http://g1.globo.com/distritofederal/noticia/2014/09/com-livros-achados-no-lixo-morador-do-df-aprende-ler-e-se-torna-medico.html>. Consulta em: 15 de jan. 2020.

10 "Pegava livros no lixo: ex-catador de Brasília conta como virou médico", publicado em UOL São Paulo, por Bruna Souza Cruz, em 25/07/2014. <https://educacao.uol.com.br/noticias/2014/07/25/pegavalivros-no-lixo-ex-catador-de-brasilia-conta-como-virou-medico.htm>. Consulta em: 15 de jan. 2020.

11 "Menino pobre descobre vocação nos livros que catava no lixo e vira médico", publicado na Globo.com, via G1, matéria do Globo Repórter, de 11/09/2015. Disponível em: $<$ http://g1.globo.com/globo-reporter/noticia/2015/09/menino-pobre-descobre-vocacao-nos-livros-quecatava-no-lixo-e-vira-medico.html >. Consulta em: 15 de jan. 2020.

12 "Inspirado nos livros do lixo, ex-catador virou médico", publicado no GGN, por Patrícia Faermann, em 27/07/2014.Disponível em: <https://jornalggn.com.br/trabalho/inspirado-nos-livros-do-lixo-ex-catadorvirou-medico/>. Consulta em: 22 de fev. 2020.

${ }^{13}$ Do texto publicado no portal G1, intitulado "Com livros achados no lixo, morador do DF aprende a ler e se torna médico".

${ }^{14}$ Do texto publicado no portal UOL, intitulado "Pegava livros no lixo: ex-catador de Brasília conta como virou médico".
} 
Todos esses textos adotam um tom proselitista em relação à leitura: a leitura cura, salva, alimenta, transporta para outros mundos, faz sonhar, inspira e por isso emancipa socialmente. Também reforçam a ideia de superação como resultante da iniciativa individual, do esforço próprio, heroico dos destinados. Em todos eles se explora o caráter surpreendente e exemplar desses sujeitos e de sua relação com os livros e a leitura, assim como do poder transformador deste objeto e desta prática. Em todos eles o livro é o objeto de leitura priorizado no que é enunciado nessas narrativas de vida. Como objeto da cultura de prestígio, ele divide espaço nessa narrativa com os discos de música erudita, clássica.

Não há espaço, nesses textos, para o papel da escola pública, dos professores, de outros incentivadores, mediadores e formadores das competências de leitura junto a esses sujeitos, a ponto de nesta história até o aprendizado da decodificação ter se dado de forma espontânea, solitária, privada, sem mediação ou apoio formal ou institucional. Não há sobretudo espaço para as políticas sociais e culturais e seu papel na vida desses sujeitos. A grande vedete dessas narrativas é o livro e a leitura, e os heróis, esses "novos leitores", que entraram como penetras, no universo da leitura, que são apresentados em sua autonomia, força de vontade, capacidade de superação e excepcionalidade.

Não é difícil deflagrarmos nesses textos uma série de discursos dominantes e consensuais sobre a leitura, como já constatamos: a afirmação da importância da leitura como inspiração para a vida; a valorização da leitura como hábito; a reiteração da prática de leitura prototípica que goza de prestígio, a saber, a de ler livros e em especial de literatura, relacionados portanto a uma prática espontânea, por prazer e entretenimento, de preferência culto, instruído, o que remonta à representação clássica da prática burguesa da leitura do século XIX, segundo a qual se construiu a idealização de uma elite ociosa que lia, sempre, muito, normalmente livros clássicos, porque dispunha e valorizava o exercício desse ócio ilustrado ${ }^{15}$, de grande prestígio, em especial se contrastado com o trabalho braçal e servil. Essa imagem idealizada outorga prestígio, mas principalmente atua como maneira eficaz de ostentar poder e de justificar as diferenças sociais.

Aliados a essa representação elitista das práticas culturais, em especial da leitura, emergem outros discursos, que de modo mais direto se filiam à ideologia do mundo capitalista: aquele da aposta no indivíduo, no seu “desejo", liberdade, escolha, poder de

${ }^{15}$ Tal como aborda o tema, Márcia Abreu (2001). 
decisão e em seus gestos individuais e de âmbito privado que seriam os responsáveis por sua "conquista". Há, assim, um apagamento sistemático de outros agentes, fatores, contingências, conjunturas, sobretudo aqueles de ordem política, das políticas de promoção da diminuição de desigualdade social. Não há política nem sociedade. Há somente indivíduos, empreendedores de si mesmos.

\section{Da cumplicidade à resistência}

Nesse e em tantos outros textos que abordam o mesmo tema e difundem os mesmos discursos sobre a leitura, testemunhamos uma relativa suspensão temporária do anonimato dos sujeitos cujas vidas ali são narradas. Essas vidas, no entanto, são lembradas sob a égide da cultura do espetáculo e à serviço da ideologia meritocrática.

Nessas notícias, reportagens e postagens, assim como nos comentários de seus leitores, estamos diante da lógica midiática típica e mais bem-acabada da "espetacularização"16. Essas vidas e esses sujeitos são feitos cúmplices do espetáculo midiático. Nós, espectadores, também. Nessas notícias são mobilizados nossos afetos, tão ao gosto dessa lógica. Explora-se nesses textos o caráter surpreendente, inusitado, improvável daquilo que se apresenta. $\mathrm{O}$ que se visa é o apelo a emoções muito familiares: neles, o sentimento de pertença, de orgulho, de realização; em nós, a comoção, a comiseração, o encantamento com uma história de vida exemplar, com a qual se identificar.

No bojo dessas emoções, pavimenta-se a promoção da adesão ao discurso meritocrático, ou seja, a crença na decisão, na escolha e na força de vontade do indivíduo, que quando quer, faz; que quando quer, vence; que quando quer, pode. Nem na formulação dos textos nem nos comentários que geraram se encontram, entre essas emoções suscitadas, a indignação, a revolta e a denúncia das condições desiguais que, de antemão, impõem a precariedade a tantas vidas que tão cedo são condenadas à impossibilidade, ao fracasso, à humilhação e à resignação com sua condição, e que ficam à mercê de um golpe de sorte do destino, ou que se sujeitam a situações sobrehumanas e sub-humanas para lutar contra essas condições e superá-las.

Desfilam-se nesses textos da mídia todos os chavões sobre a leitura. Eles fazem parte desse dispositivo de poder, dessa ordem do dizível, ostentável (e também ridicularizável dos desvios) sobre a leitura e os leitores. Esses textos também desfilam o discurso dominante que atribui ao indivíduo a responsabilidade exclusiva por sua

${ }^{16}$ Conforme caracteriza Guy Debord (2000). 
emancipação. Em nenhum deles se chama a atenção para o escândalo, para a vergonha nacional, para o crime que é condenar crianças e jovens às vidas sub-humanas que dependem dos restos dos outros. Não há indignação alguma com essas histórias de vida precarizada, pauperizada, semelhante a de parte não negligenciável da sociedade brasileira. A referência a sua miséria é trazida para ilustrar o tamanho de sua conquista individual. O que sobressai, o que é explorado, é a mais perversa propaganda da meritocracia, tão ao gosto de nossa elite.

A visada assistencialista com que se trata a leitura, e o tom apologético da superação individual com a dose de espetáculo tão própria do estilo da grande mídia, é, em geral, cega e produtora de cegueira para as dimensões sociais, culturais e sobretudo políticas implicadas na distribuição desigual do direito a essa prática. Essa visada resulta do efeito de evidência do que foi enunciado sobre a leitura.

Esses indivíduos infames, tal como o caso que apresentamos brevemente aqui, e que ocupam cinco minutos de atenção da mídia, venceram uma série de adversidades. Sua história de vida é de fato tocante e inspiradora. Eles são verdadeiros "batalhadores" (SOUZA, 2012), que merecem todo nosso respeito e admiração. A questão que deve, no entanto, deter nossa atenção é a de compreender como suas histórias de vida são apropriadas, as razões pelas quais suas histórias passam a ter, ainda que rapidamente, o interesse da mídia em uma determinada conjuntura, e o que efetivamente é dito, reproduzido e faz eco à ideologia dominante, nisso que foi dito a respeito deles, de modo a sempre beneficiar quem domina. $\mathrm{O}$ que foi dito a respeito deles nesses textos da mídia tradicional, o que foi citado como tendo sido enunciado por eles e o que foi selecionado de tudo aquilo que enunciaram sobre si e sua relação com a leitura para figurar nesses textos responde a esses discursos dominantes e consensuais.

Disso decorre a importância de analisarmos esses discursos que são produzidos e circulam sobre essa prática, de mostrarmos que eles "obedecem a regras e a transformações analisáveis" (FOUCAULT, 2000, p. 239), de mostrarmos como eles atuam na objetivação e subjetivação dos sujeitos e suas práticas, de nós como sujeitos e de nossas práticas. Não sem razão, a proposta do filósofo de se conhecer as regras de emergência dos discursos e de seu funcionamento, é tão fundamental e decisiva para as mudanças que importam. Da capacidade de reconhecermos a ascendência e o impacto do funcionamento dos discursos sobre o que em geral reproduzimos, tanto no que dizemos como no modo como agimos, se abre a possibilidade de podermos resistir a esses discursos, de podermos lutar contra e com esses discursos e as práticas que a eles 
se relacionam. Por isso, é importante devolver à leitura, como uma prática fundamental em uma sociedade letrada como a nossa, seu potencial de fomentar a transgressão, de incitar interpretações à revelia do que se nos mostram tão evidente e de modo tão regular, e de promover a indignação em relação ao que é sistematicamente invisibilizado nesses textos que falam dela, que reproduzem os discursos de longa data e entre eles uma série de estereótipos. Analisar discursos e ensinar a analisar discursos é uma forma de nos defendermos de seu impacto, de subvertermos suas lógicas, de assumirmos uma ética responsável, enfim, de fazermos política.

\section{Referências}

ABREU, Márcia. Diferença e Desigualdade: Preconceitos em Leitura. In: MARINHO, Marildes (org.). Ler e Navegar: espaços e percursos da leitura. Campinas: Mercado de Letras/ALB, 2001.

BAYARD, Pierre. Como falar dos livros que não lemos?. Rio de Janeiro: Objetiva, 2007.

BRITTO, Luiz Percival Leme \& BARZOTTO, Valdir Heitor. Promoção X Mitificação da Leitura. Em Dia: Leitura \& Crítica. Campinas: Associação de Leitura do Brasil, Agosto de 1998.

BRITTO, Luiz Percival Leme. Máximas impertinentes. Na ponta do lápis, ano XII, n. 27. p. 32-39. Julho de 2016. Disponível em: https://www.escrevendoofuturo.org.br/arquivos/5917/npl27-03ago2016.pdf. Acesso em: 09 de julho de 2020.

CURCINO, L. Da infâmia à resistência: quando se é notícia porque se lê. In: SÁ, Israel; BRAGA, Amanda (orgs.). Microfísica da resistência: Michel Foucault e as lutas antiautoritárias da contemporaneidade. Campinas: Pontes, 2020. p. 249-274.

CURCINO, Luzmara. Imprensa e discursos sobre a leitura: representações dos presidentes FHC, Lula e Dilma como leitores. EID\&A - Revista Eletrônica de Estudos Integrados em Discurso e Argumentação, Ilhéus, n. 16, Edição Especial "Discurso e argumentação na política latino-americana", p. 223-243, Set. 2018. Disponível em: http://periodicos.uesc.br/index.php/eidea/article/view/2223. Acesso em: 09 de julho de 2020.

CURCINO, Luzmara; VARELLA, Simone. Discursos sobre a leitura: uma análise de vídeo-campanhas em prol dessa prática. Revista Desenredo. V. 10, p.337-354, 2014. Disponível em: http://www.upf.br/seer/index.php/rd/article/view/4157/3091. Acesso em: 08 de julho de 2020.

CURCINO, Luzmara; PIOVEZANI, Carlos. Fazer, pensar, dizer e olhar: dispositivos de fala pública e de leitura da mídia. In: FERNANDES J. A.; SOUSA, K. M. (orgs.). Dispositivos de poder em Foucault: práticas e discursos da atualidade. Goiânia: Gráfica UFG, 2014.

DEBORD, Guy. A sociedade do espetáculo. Rio de Janeiro: Contraponto, 2000.

FOUCAULT, Michel. A vida dos homens infames. In: Ditos e Escritos: Estratégia, poder-saber. vol. IV, Rio de Janeiro: Forense Universitária, 2003a, p. 203-222. 
FOUCAUlT, Michel. Le Pouvoir Psychiatrique. Cours au collège de France, 19731974. Paris: Gallimard/Seuil, 2003b.

FOUCAULT, Michel. A arqueologia do Saber. Rio de Janeiro: Forense Universitária, 2000.

FOUCAULT, Michel. A ordem do discurso: aula inaugural no Collège de France, pronunciada em 02 de dezembro de 1970. São Paulo: Edições Loyola, 1996.

GREGolin, Maria do Rosário. Foucault e Pêcheux na construção da análise do discurso: diálogos e duelos. São Carlos: Editora Claraluz, 2004.

HÉBRARD, Jean. Peut-on faire une histoire des pratiques populaires de lecture à l'époque moderne? Les 'nouveaux lecteurs' revisités. Matériaux pour une histoire de la lecture et de ses institutions. Paris, tome 17, p. 105-140, 2005.

SOUZA, Jessé. A construção social da subcidadania: para uma sociologia política da modernidade periférica. Belo Horizonte: Editora da UFMG, 2012. 